\title{
Immune complexes activate human endothelium involving the cell-signaling HMGB1-RAGE axis in the pathogenesis of lupus vasculitis
}

\author{
Wenping Sun, Yulian Jiao, Bin Cui, Xuejun Gao, Yu Xia and Yueran Zhao
}

Systemic lupus erythematosus (SLE) is an autoimmune disease characterized by the formation of immune complexes (ICS), which contain a complex mixture of autoantigens nucleic acids, nucleic acids-associated proteins and corresponding autoantibodies. In SLE, ICS are deposited in multiple organs. Vasculopathy and vasculitis in SLE are typical complications and are associated with deposition of ICs on endothelium, endothelial activation and inflammatory cell infiltration. However, the effects of ICs on endothelial cells and the mechanisms involved remain unclear. In this study, we have demonstrated for the first time that ICs upregulated cell surface expression of the receptor for advanced glycation end products (RAGE), the expression of intercellular adhesion molecule-1 (ICAM-1), vascular cell adhesion molecule-1 (VCAM-1), increased the secretion of the chemokines interleukin 8 (IL-8), monocyte chemoattractant protein-1 (MCP-1), the proinflammatoy cytokines interleukin 6 (IL-6), tumor necrosis factor- $\alpha$ (TNF- $\alpha$ ) and promoted the activation of the transcription factor NF- $\kappa$ B p65 in human endothelial cells $(P<0.05)$. ICs also increased transendothelial migration of monocytes $(P<0.05)$. One of the mechanisms underlying these activating effects of ICs on human endothelial cells involves cell signaling by high-mobility group box 1 protein (HMGB1)-RAGE axis, as these effects can be partially blocked by HMGB1 A-box, soluble RAGE (sRAGE), SB203580, PD98059, Bay $117082(P<0.05)$ and co-treatment with these agents $(P<0.05)$. In conclusion, ICs elicit proinflammatory responses in human endothelial cells and alter their function involving cellular signaling via the HMGB1-RAGE axis in the pathogenesis of SLE vasculitis.

Laboratory Investigation (2013) 93, 626-638; doi:10.1038/labinvest.2013.61; published online 29 April 2013

KEYWORDS: endothelial activation; HMGB1-RAGE axis; immune complexes; lupus vasculitis; NF- $\kappa$ B; systemic lupus erythematosus

Systemic lupus erythematosus (SLE) is a chronic autoimmune disease, which is characterized by the formation of immune complexes (ICs). The constitution of ICs is very complex, and they typically contain autoantigens nucleic acids, nucleic acids-associated proteins, and corresponding autoantibodies. ${ }^{1-3}$ The clearance of apoptotic cells by monocytes/macrophages is impaired in patients with SLE, which results in secondary necrosis, and the release of autoantigens nucleic acids and nucleic acids-associated proteins from the nuclei of these secondary necrotic cells. ${ }^{4,5}$ The generation of corresponding autoantibodies that are targeted against these nuclear autoantigens, such as antidouble-stranded DNA (dsDNA) antibodies leads to the formation of ICs. ${ }^{1}$ Deposition of ICs on target organs, such as the skin and kidney, results in end organ damage. ${ }^{3}$
Vasculopathy and vasculitis, which are typical complications of SLE, are reported in 10-40\% of SLE patients and are usually seen in cutaneous vessels, renal glomeruli, coronary and brain blood vessels. ${ }^{6,7}$ Vasculopathy and vasculitis could be associated with the deposition of ICs on endothelium, leading to endothelial cell activation and inflammatory cell infiltration into the inflammatory sites. ${ }^{6-9}$ However, the effects of ICs on endothelial cells and the potential mechanisms involved remain unclear.

HMGB1, also known as amphoterin, which belongs to the nucleic acids-associated binding proteins, is an essential component of ICs. ${ }^{1-3}$ HMGB1 is expressed in almost all eukaryotic cells and is located mainly in the nucleus, where it binds to nucleotides to stabilize the structure of nucleosomes. By inducing DNA bending, HMGB1 regulates 
transcription. ${ }^{10}$ In SLE patients, HMGB1-nucleic acids complexes are released from secondary necrotic cells and forms ICs with the corresponding autoantibodies, which are significantly elevated in the sera. ${ }^{1,3,10,11}$ Depositon of HMGB1-containing ICs are also found in target tissues, such as the skin ${ }^{12}$ and kidney, ${ }^{13}$ where they contribute to both chronic inflammation and tissue injury. The proinflammatory activity of HMGB1 is mostly attributed to its ligation with RAGE, ${ }^{14}$ which is a member of the immunoglobulin superfamily of cell surface molecules. RAGE is a central signal transduction receptor for HMGB1-modified adducts, ${ }^{14}$ and is expressed on a variety of cells, including endothelial cells, monocytes and macrophages, and transduces its signals via the classic activation of the NF- $\kappa \mathrm{B}$ transcription factor family member p65. ${ }^{14-18}$ Furthermore, RAGE signaling through the NF- $\kappa \mathrm{B}$ p65 pathway regulates the expression of RAGE itself. ${ }^{14}$

HMGB1 is an important component of ICs, ${ }^{1-3}$ and the inflammatory activity of HMGB1 is mostly attributed to its ligation with RAGE. ${ }^{14}$ Thus, cell signaling via the HMGB1RAGE axis might have crucial roles in the effects of ICs on endothelial cells. However, the role played by cell signaling via the HMGB1-RAGE axis in response to the effects of ICs on endothelial cells has not been previously evaluated. We therefore sought to evaluate the involvement of the cellsignaling pathway via the HMGB1-RAGE axis in response to the interaction of ICs with endothelial cells. We also sought to determine whether this aforementioned pathway, is one potential mechanism that is mediated by ICs on interaction with human endothelial cells.

The effects of HMGB1 can be specifically blocked by HMGB1 A-box. ${ }^{19,20}$ Similarly, RAGE can be blocked by sRAGE. $^{21,22}$ HMGB1 A-box, sRAGE, Bay $117082^{23}$ and combinations of these blocking agents were used to block the effects of the HMGB1 component in ICs, and to attenuate the signaling mediated by RAGE, and the NF- $\kappa \mathrm{B}$ p 65 pathway, and to combine their effects in an attempt to determine whether ICs activate human endothelial cells via the HMGB1-RAGE cell-signaling axis. Additionally, the p38 mitogen-activated protein kinase (MAPK), and the extracellular signal-related kinases 1 and 2 (ERK1/2) transduction pathways might be involved in the RAGE-mediated signaling pathway that directs NF- $\kappa \mathrm{B}$ activation. ${ }^{14,16,24-26}$ Specific inhibitors of p38 MAPK (eg, SB203580) and ERK1/2 (eg, PD98059) ${ }^{16}$ were also used to clarify the respective contributions of the p38 MAPK and ERK1/2 signal transduction pathways on cytokine secretion response on activation of human endothelial cells by ICs.

In the current study, we have explored the effects of ICs on endothelial cells. Further, we have attempted to evaluate the involvement of the HMGB1-RAGE axis as one putative signal transduction mechanism that could mediate the effects of ICs following their interaction with human endothelial cells, which may have an important role in SLE vasculitis.

\section{MATERIALS AND METHODS Reagents and Antibodies}

Cell culture reagents and TRIzol were obtained from Invitrogen (Carlsbad, CA, USA) and Hyclone (Portland, OR, USA). Protein G columns were obtained from Millipore (Billerica, MA, USA). PrimeScript RT reagent Kit, SYBR Premix Ex TaqTM II was obtained from TaKaRa Biotechnology (Japan). NE-PER Nuclear and Cytoplasmic Extraction Reagents were obtained from Pierce Biotechnology (Rockford, IL, USA). Quantikine enzyme-linked immunosorbent assay (ELISA) kits for the determination of IL-8, MCP-1, IL-6, TNF- $\alpha$ and IL- $1 \beta$ levels were obtained from R\&D Systems (Minneapolis, MN, USA). Transwell Permeable Support was obtained from Corning (Lowell, MA, USA). Bay 117082 was obtained from Axxora (San Diego, CA, USA). Mouse monoclonal anti-RAGE, mouse monoclonal anti-ICAM-1, mouse monoclonal anti-VCAM-1, rabbit monoclonal anti-NF- $\kappa \mathrm{B}$ p65, rabbit monoclonal anti-I $\kappa \mathrm{B}-\alpha$ and rabbit monoclonal anti-histone $\mathrm{H} 3$ were all obtained from Abcam (Cambridge, MA, USA). Mouse monoclonal antibody against $\beta$-actin was obtained from Santa Cruz Biotechnology (Santa Cruz, CA, USA).

\section{Preparation of ICs and Identification of its Effective Components}

ICs were prepared as previously described. ${ }^{2,27-30}$

\section{Induction of Apoptosis and Preparation of Cell Supernatants}

Human U937 cells were resuspended at a density of $5 \times$ $10^{7}$ cells $/ \mathrm{ml}$ in macrophage-SFM medium and irradiated with ultraviolet (UV) light in $2 \mathrm{ml}$ volumes of a cell suspension in 9.4- $\mathrm{cm}^{2}$ petri-dishes using a $480 \mathrm{~mJ} \mathrm{UV}$ cross-linking instrument (UVP, USA). The UV-treated cells were cultured for $24 \mathrm{~h}$ at $37^{\circ} \mathrm{C}$ in a $5 \% \mathrm{CO}_{2}$ in air atmosphere. The culture supernatants were collected to prepare ICs after centrifugation $(400 \times g$ for $5 \mathrm{~min})$. Cell death was confirmed by staining with fluorescein isothiocyanate (FITC)-labeled annexin $\mathrm{V}$ and propidium iodide (PI) and subsequent analysis by flow cytometry (FCM; Figure 1). The supernatants of untreated U937 cells were used as negative control. In the experiments, the concentration of supernatants from UVtreated and untreated cells was kept constant at 50\%.

\section{Sera and Preparation of IgG}

We recruited 36 SLE patients who were confirmed to fulfill the 1982 criteria for the diagnosis of SLE. The patients fulfilled 4-10 features in the American College of Rheumatology (ACR) classification criteria for SLE (median 6). Disease activity was measured by the SLE disease activity index (SLEDAI). Serum was collected from venous blood and stored at $-80^{\circ} \mathrm{C}$. Serum samples used in the study were pooled, filtered through a $0.45-\mu \mathrm{m}$ filter and DNase I treated to remove endogenously bound DNA. The IgG was purified from the pooled serum samples on a protein $G$ column (Millipore) 


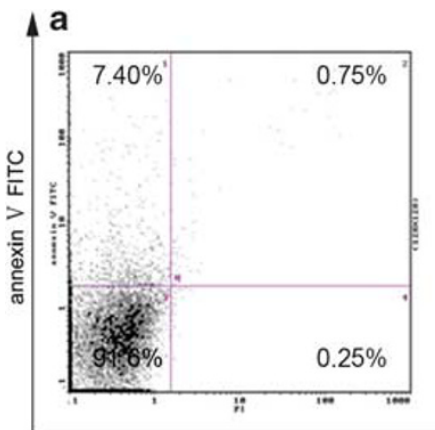

b

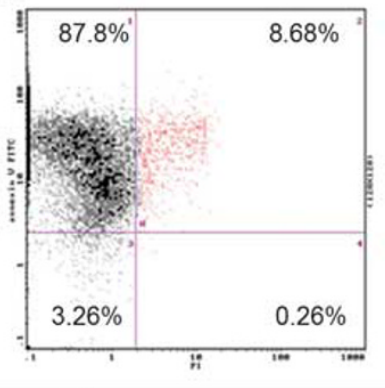

$\mathrm{P}$ c

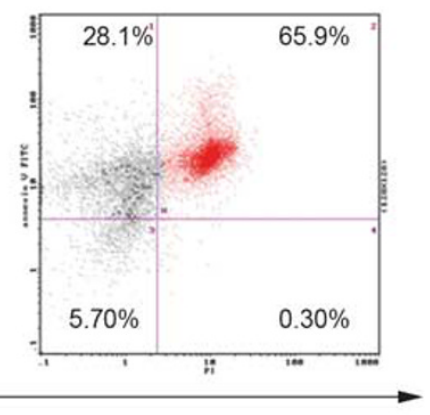

Figure 1 Induction of cellular apoptosis. (a) Normal U937 cells (without UV light treatment). (b). UV light-treated U937 cells directly after treatment. (c) UV light-treated U937 cells with culture for $24 \mathrm{~h}$ after treatment. Cells were stained with FITC-labeled annexin V and propidium iodide (PI) and analyzed by flow cytometry. Results of representative experiments are shown.

Table 1 Characteristics of SLE patients and healthy controls

\begin{tabular}{lcc}
\hline Characteristics & SLE patients $(n=36)$ & Healthy controls $(n=36)$ \\
\hline Age (years, mean (range)) & $38.5(14-58)$ & $38(16-56)$ \\
Sex $(n$, males/females) & $5 / 31$ & $5 / 31$ \\
Disease duration (years, mean (range)) & $10.5(1-38)$ & $8.6 \pm 5.8$ \\
SLE-DAl (mean \pm s.d.) & $10.3 \pm 6.0$ & $3.1 \pm 1.0$ \\
Active $(n=26)$ & $36,17.69 \pm 9.82,1.64-38.32$ & $36,10.67 \pm 2,52,7.40-15.89$ \\
Inactive $(n=10)$ & $35,132.05 \pm 156.46,15.63-834.18$ & $8,30.70 \pm 15.26,11.69-60.24$ \\
IgG (g/l; $n$, mean \pm s.d., range) & $30,24.37 \pm 30.34,3.68-135.92$ & $4,6.58 \pm 4.85,2.12-12.94$ \\
Anti-dsDNA (RU/ml; $n$, mean \pm s.d., range) & $32,32.20 \pm 38.39,5.19-146.41$ & $4,6.22 \pm 4.80,2.64-13.21$ \\
Anti-Sm (RU/ml; $n$, mean \pm s.d., range) & & \\
AnuA (RU/ml; $n$, mean \pm s.d., range) & & \\
\hline
\end{tabular}

Abbreviation: SLE-DAI, systemic lupus erythematosus-diease activity index.

according to the manufacturer's instructions, then dialyzed against RPMI 1640 , and stored at $-80{ }^{\circ} \mathrm{C}$. The concentration of IgG used in the experiments was $1 \mathrm{mg} / \mathrm{ml}$. IgG obtained from the SLE serum samples were detected by a nephelometric assay kit, obtained from Dade Behring Marburg $\mathrm{GmbH}$ (Marburg, Germany). Autoantibodies of the IgG class, which were targeted against dsDNA, Sm and the nucleosome, were detected by ELISA kits that were obtained from EUROIMMUN according to the manufacturers' instructions. The upper limit recommended by EUROIMMUN was 100 international units (IU)/ml for antidsDNA, and 20 relative units (RU)/ml for anti-Sm and AnuA. Serum samples from 36 age- and sex-matched healthy blood donors were used for preparation of normal IgG in the same way. Subsequently, autoantibodies of the IgG class against dsDNA, Sm and nucleosome were not detected to be abnormal in any of the recruited healthy blood donors. The characteristics of the SLE patients and healthy normal controls for this study are shown in Table 1. The study was approved by the ethics committee of Shandong University and informed consent was obtained from all the blood donors.

\section{Preparation of ICs}

ICs were combined with $50 \%$ volumes of the late apoptotic cell supernatants and lupus IgG at $1 \mathrm{mg} / \mathrm{ml}$. The $\operatorname{IgG}$ obtained from healthy donors alone, lupus IgG alone, supernatants of untreated U937 cells and IgG from healthy donors, supernatants of untreated U937 cells and lupus IgG, supernatants of UV-treated U937 cells and IgG from healthy donors with the same concentration all served as negative controls in the experiments. The effective component of HMGB1 in the prepared ICs and the negative controls were identified by western immunoblot analysis (Figure 2).

\section{Expression and Purification of HMGB1 A-box and SRAGE Proteins}

The primers for amplification of complementary DNA (cDNA) encoding the A-box protein of HMGB-1 (261 bp)

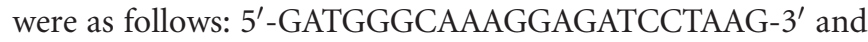




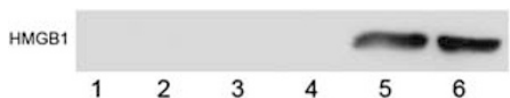

Figure 2 Western immunoblot showing that HMGB1 is included in the prepared ICs. Detection of HMGB1 protein in the prepared IC samples and in the negative controls by western immunoblot analysis. Lanes: (1) control IgG alone; (2) lupus IgG alone; (3) supernatants of untreated U937 cells and control IgG; (4) supernatants of untreated U937 cells and lupus IgG; (5) supernatants of UV-treated U937 cells and control IgG; and (6) supernatants of UV-treated U937 cells and lupus IgG (ICs).

5'-TCACTTTTTTGTCTCCCCTTTGGG-3'. A stop codon was added to ensure the accuracy of the protein size. The PCR products were subcloned into an expression vector (pGEX) with a GST tag (Amersham Pharmacia, USA). The recombinant plasmids were then transformed into the protease-deficient Escherichia coli strain BL21 (Novagen, Germany) and grown in 2-YT medium. Protein expression was induced by isopropyl D-thiogalactopyranoside (IPTG). HMGB1 A-box proteins were purified using glutathionesepharose affinity columns (Amersham Pharmacia, USA). DNase I was added to glutathione-sepharose beads and incubated for $20 \mathrm{~min}$ at room temperature in buffer containing $100 \mathrm{mM}$ sodium acetate and $5 \mathrm{mM}$ magnesium chloride to remove any contaminating DNA. HMGB1 A-box proteins were further purified by a polymyxin B column (Pierce, USA) to remove contaminating endotoxin. The purity and integrity of the proteins were verified by Coomassie blue staining after sodium dodecylsulfate-polyacrylamide gel electrophoresis (SDS-PAGE) to reveal that the purity was $>85 \%$.

sRAGE was isolated from cell culture supernatants of human embryonic kidney (HEK)-293 cells, which were stably transfected with the vector pSecTag2B (Invitrogen, USA) containing sRAGE cDNA. The recombinant sRAGE was then purified as described previously. ${ }^{22}$

\section{Cell Culture and Treatment}

The human umbilical vein endothelial cell-line, CRL-1730, was obtained from the American Type Culture Collection (ATCC; Manassas, VA, USA) and grown in F-12K medium supplemented with $0.1 \mathrm{mg} / \mathrm{ml}$ heparin, $0.05 \mathrm{mg} / \mathrm{ml}$ endothelial cell growth supplement and $10 \%$ fetal bovine serum. Human U937 monocytic cells were also obtained from the ATCC and maintained in RPMI-1640 medium supplemented with $10 \%$ fetal bovine serum, 100 units $/ \mathrm{ml}$ penicillin-G and $100 \mu \mathrm{g} / \mathrm{ml}$ streptomycin sulfate. Cells were grown at $37^{\circ} \mathrm{C}$ in a $5 \% \mathrm{CO}_{2}$ and air atmosphere. Human CRL-1730 cells were treated as described in the experiments except for special circumstances as indicated in the text.

For ICs stimulation and blocking assays, human CRL-1730 cells were seeded into $6 \mathrm{~cm}$-dishes at $80 \%$ confluent monolayers and pretreated with HMGB1 A-box $(10 \mu \mathrm{g} / \mathrm{ml})$, sRAGE $(20 \mu \mathrm{g} / \mathrm{ml})$ SB203580 $(10 \mu \mathrm{M})$, PD98059 $(25 \mu \mathrm{M})$, Bay117082 $(1 \mu \mathrm{M})$ or combination of them for $1 \mathrm{~h}$ before the addition of ICs. After incubation for $2 \mathrm{~h}$, immunocytochemistry (ICC), immunofluorescence (IF) and western blot analyses of NF- $\kappa \mathrm{B}$ family member p65 levels in the nucleus were performed. After incubation for $6 \mathrm{~h}$, RAGE, ICAM-1, VCAM-1, IL-8, MCP-1, IL- 6 , TNF- $\alpha$ and IL- $1 \beta$ mRNA levels were detected. After incubation for $16 \mathrm{~h}$, cell surface RAGE, ICAM-1 and VCAM-1 proteins expression levels were analyzed by ICC, IF, FCM or cellular enzyme-linked immunosorbent assay (cellular ELISA) analysis. After incubation for $24 \mathrm{~h}$, the concentration of cytokines IL- 8, MCP-1, IL- 6 , TNF- $\alpha$ and IL-1 $\beta$ in the cell-free supernatants were detected.

For transendothelial migration experiments, human CRL-1730 cells were seeded on gelatin-coated permeable Transwell filters $(8.0 \mu \mathrm{m}$ polycarbonate membrane, $6.5 \mathrm{~mm}$ insert, 24-well plates, Corning) to form a monolayer and pretreated with blocking agents and ICs as described above for $24 \mathrm{~h}$ before assessment of monocyte migration.

For cell viability assay, human CRL-1730 cells were seeded into 24-well plates at a density of $10^{5}$ cells/well, and allowed to attach and grow overnight to confluence, and then incubated with control medium alone, HMGB1 A-box $(10 \mu \mathrm{g} / \mathrm{ml})$, sRAGE $(20 \mu \mathrm{g} / \mathrm{ml})$, SB203580 $(10 \mu \mathrm{M})$, PD98059 $(25 \mu \mathrm{M})$, Bay $117082(1 \mu \mathrm{M})$ or combinations of these agents for $24 \mathrm{~h}$.

\section{Flow Cytometry}

Cells were collected and washed twice with PBS, then incubated with mouse monoclonal antibodies against RAGE, ICAM-1 or VCAM-1 for 30 min at $4{ }^{\circ} \mathrm{C}$. After washing with PBS, human CRL-1730 cells were stained with FITCconjugated goat anti-mouse polyclonal antibodies for $30 \mathrm{~min}$ at $4{ }^{\circ} \mathrm{C}$ in the dark. FCM analysis was then performed. Cells incubated without the primary antibody were used as blank controls. Immunofluorescence intensity was quantified using a flow cytometer (Epics XL, Beckman Coulter, USA). Data were analyzed using system II version 3.0 software. The results are presented as the mean fluorescence intensity, and are expressed in arbitrary units of fluorescence as fold changes of the level of cell surface molecule expression relative to the negative control.

\section{Quantitative Real-Time PCR}

Cells were harvested by brief centrifugation, and total RNA was isolated using TRIzol reagent. Total RNA $(1 \mu \mathrm{g})$ was reverse-transcribed into cDNA using a PrimeScript RT reagent Kit. Quantitative real-time PCR was performed with an ABI PRISM 7500 Fast Real-Time PCR System (Applied Biosystems, Foster City, CA, USA) using SYBR Premix Ex TaqTM II according to the manufacturer's instructions. Primer sequences were designed and synthesized by TaRaKa (Supplementary Table S1). The housekeeping gene GAPDH (glyceraldehyde-3-phosphate dehydrogenase) was used as an endogenous control. To ensure experimental accuracy, all reactions were performed in triplicate. The relative analysis of the data was performed using ABI Prism SDS 1.4 software. Quantified results were expressed as the cycle threshold (CT) 
values. Relative quantification of fold changes in gene expression were analyzed by the $2^{-\Delta \Delta \mathrm{CT}}$ method, which is used to compare gene expression in different treatment groups relative to the negative control group.

\section{Immunofluorescence}

Cells were grown on poly-D-lysine-coated coverslips in F-12K medium containing 10\% FCS. Following treatment with ICs for the indicated times, cells were fixed for $15 \mathrm{~min}$ in $4 \%$ paraformaldehyde. After washing, cells were permeabilized for $10 \mathrm{~min}$ in PBS containing $0.2 \%$ Triton X-100, and nonspecific binding was blocked by incubation with PBS containing 2\% BSA. For immunofluorescence staining, cells were incubated with mouse monoclonal anti-RAGE $(1: 100)$ or rabbit monoclonal anti-p65 (1:100) at $4{ }^{\circ} \mathrm{C}$ overnight. Samples were then incubated with Rhodamine (TRITC)conjugated anti-mouse or anti-rabbit $\operatorname{IgG}(1: 100)$ at $37^{\circ} \mathrm{C}$ for $30 \mathrm{~min}$. DAPI (4',6-diamidino-2-phenylindole) was used to counterstain the nucleus. The fluorescence signals were visualized by fluorescence microscopy (Nicon ECLIPSE Ti-S, Japan) and were analyzed using NIS-Elements D 3.2 software.

\section{Immunocytochemistry}

Immunocytochemistry was performed with streptavidin/ peroxidase staining kits. Cells were grown on poly-D-lysinecoated coverslips in F-12K medium containing 10\% FCS. Following treatment with ICs for the indicated times, cells were fixed for $15 \mathrm{~min}$ in $4 \%$ paraformaldehyde and permeabilized for $10 \mathrm{~min}$ in PBS containing $0.2 \%$ Triton X-100. After washing in PBS, the immunocytochemical staining was performed according to the manufacturer's instructions. Mouse monoclonal anti-RAGE (1:500) and rabbit monoclonal anti-p65 (1:500) were used as primary antibodies. Cells were incubated with the primary antibody for $2 \mathrm{~h}$ at room temperature. Detection of positively stained signals was done using $\mathrm{DAB}$ (3,3-diaminobenzidine-tetrahydrochloride) kits according to the manufacturer's instructions and the slides were counterstained with hematoxylin. The images were visualized by microscopy (Leica DM4000B, Germany) and were analyzed using Leica Application Suite V 3.6 software.

\section{Cellular ELISA}

The expression of cell surface RAGE, ICAM-1 and VCAM-1 were quantified by cellular ELISA. Human CRL-1730 cells were seeded into 96-well plates at a density of $2 \times 10^{4}$ cells/ well. After incubation with various stimuli for the indicated times, cells were fixed in $4 \%$ paraformaldehyde and incubated for $30 \mathrm{~min}$ at room temperature with normal goat serum used for blocking against non-specific binding. Cell surface molecules were labeled with monoclonal antibodies against RAGE, ICAM-1 or VCAM-1 for $1 \mathrm{~h}$ and then for 30 min with HRP-conjugated secondary antibodies at room temperature. The cells were washed and ICs were detected by incubation in $\operatorname{TMB}\left(3,3^{\prime}, 5,5^{\prime}\right.$-tetramethylbenzidine $)$ peroxidase substrate for $15 \mathrm{~min}$. The reaction was then terminated with sulphuric acid $(1 \mathrm{~mol} / \mathrm{l})$, and absorbance values were measured at $450 \mathrm{~nm}$ using a Spectrophotometer (SpectraMax $\mathrm{M}_{2}$, Molecular Devices, USA).

\section{ELISA}

The secretion of IL- 8, MCP- 1 IL- 6 , TNF- $\alpha$ and IL- $1 \beta$ into the cell-free supernatants was determined by Quantikine ELISA kits (R\&D Systems) according to the manufacturer's protocols. Culture medium alone without cells was incubated under the same conditions and used as a blank control.

\section{Transendothelial Migration}

Before migration assays, human CRL-1730 cell monolayers were cultured on gelatin-coated Transwell Permeable Supports and pretreated with blocking agents and ICs as described above for $24 \mathrm{~h}$. RPMI 1640 medium containing $10 \%$ FBS $(500 \mu \mathrm{l})$ was placed in the bottom chamber of Transwell inserts, and $200 \mu \mathrm{l} \mathrm{U937}$ cells (at a density of $10^{6} \mathrm{cells} / \mathrm{ml}$ ) were added to the upper chamber. After incubation for $20 \mathrm{~h}$, the cells that had transmigrated to the lower chamber were harvested and counted using a TC10 Automated Cell Counter (Bio-Rad, USA).

\section{Cell Nuclear and Cytoplasmic Protein Extraction and Western Immunoblot Analysis}

Cell nuclear and cytoplasmic protein extraction was done with the NE-PER Nuclear and Cytoplasmic Extraction Reagents. The protein concentrations were determined by the BCA Protein Assay Reagent Kit. Equal quantities of proteins from differently treated cells were separated by $10 \%$ SDS-PAGE and transferred onto nitrocellulose membranes. Membranes were blocked with 5\% non-fat dry milk proteins in TBST for $1 \mathrm{~h}$ at room temperature and then incubated with the indicated primary antibodies at $4{ }^{\circ} \mathrm{C}$ overnight. Membranes were then incubated with the HRP-conjugated secondary antibodies for $1 \mathrm{~h}$ at room temperature. Chemiluminescence was detected using a LAS 4000 mini (Fujufilm, Japan), and the protein bands were quantified by densitometry using the Multi-Gauge V 3.2 software program. For detection of nuclear levels of the NF- $\kappa \mathrm{B}$ p65, rabbit monoclonal anti-NF- $\kappa \mathrm{B}$ p65 was used, and rabbit monoclonal anti-histone $\mathrm{H} 3$ antibody was used as a loading control. For detection of cytoplasmic $\mathrm{I} \kappa \mathrm{B}-\alpha$ levels, rabbit monoclonal anti- $\mathrm{I} \kappa \mathrm{B}-\alpha$ was used, and rabbit monoclonal anti $\beta$-actin antibody was used as an equal protein loading control.

\section{Cell Viability Test}

Cells were harvested and isolated by centrifugation for $5 \mathrm{~min}$ at $1000 \mathrm{rpm}$, and total cell counts were measured using a TC10 Automated Cell Counter (Bio-Rad, USA). The number of viable cells was determined by counting the numbers of Trypan blue impermeable cells using a hemocytometer. 
In another test, cell viability was determined using the CCK-8 kit according to the manufacturer's protocol.

\section{Statistical Analysis}

Statistical analyses were performed using the SPSS statistical software version 17.0. Unless otherwise indicated, data are presented as mean \pm s.e. Differences of group comparisons were analyzed using one-way ANOVA and subsequent appropriate post-hoc analysis by unpaired Student's $t$-tests. A $P$ value $<0.05$ was considered statistically significant.

\section{RESULTS}

ICs Upregulate RAGE Expression Involving the CellSignaling HMGB1-RAGE Axis in Human Endothelial Cells Human CRL-1730 cells were treated with ICs and the negative controls for $6 \mathrm{~h}$. ICs increased the mRNA levels of RAGE approximately threefold, whereas the negative controls showed no significant effects on mRNA levels of RAGE (Figure 3a). After incubation for $16 \mathrm{~h}$, the expression of cell surface RAGE was determined by FCM (Figure 3b) and cellular ELISA (Supplementary Figure S1) and levels were found to correspond well with the changes seen for the mRNA levels $(P<0.05)$. Thus, only ICs had a significant activating effect on the expression of cell surface RAGE $(P<0.05)$. The IgG from healthy donors alone, supernatants of untreated U937 cells and IgG from healthy donors do not have any effects on the expression of RAGE. Lupus IgG alone, supernatants of untreated U937 cells and lupus IgG, supernatants of UV-treated U937 cells and IgG from healthy donors showed no significant effects on the expression of RAGE in human endothelial cells. As all negative control treatments had no significant effect, we selected only the supernatants of untreated U937 cells and IgG from healthy donors as the negative control to exclude the material influence of ICs on human endothelial cells in the following experiments.

Human CRL-1730 cells were treated with ICs for $16 \mathrm{~h}$ (Supplementary Figures S2 and S3), and ICs were found to upregulate the expression of cell surface RAGE on human CRL-1730 cells, compared with the negative control cells. RAGE is the receptor for HMGB1 and signals via the NF- $\kappa$ B pathway. Thus, we next examined whether the increased expression of RAGE induced by ICs involves cell signaling via the HMGB1-RAGE axis. Human CRL-1730 cells were pretreated with HMGB1 A-box $(10 \mu \mathrm{g} / \mathrm{ml})$ or Bay $117082\left(10^{-6}\right.$ M) for $1 \mathrm{~h}$ before treatment with ICs for $6 \mathrm{~h}$. CRL-1730 cells incubated with ICs for $6 \mathrm{~h}$ showed approximately a threefold increase in RAGE mRNA levels (Figure 3a); both HMGB1 A-box and Bay117082 suppressed this upregulation in expression of RAGE mRNA $(P<0.05$, Figure 3a) induced by ICs. Analysis of cell surface RAGE protein expression by FCM (Figure $3 \mathrm{~b}$ ) and cellular ELISA (Supplementary Figure S1) corresponded well with the mRNA levels determined $(P<0.05)$.
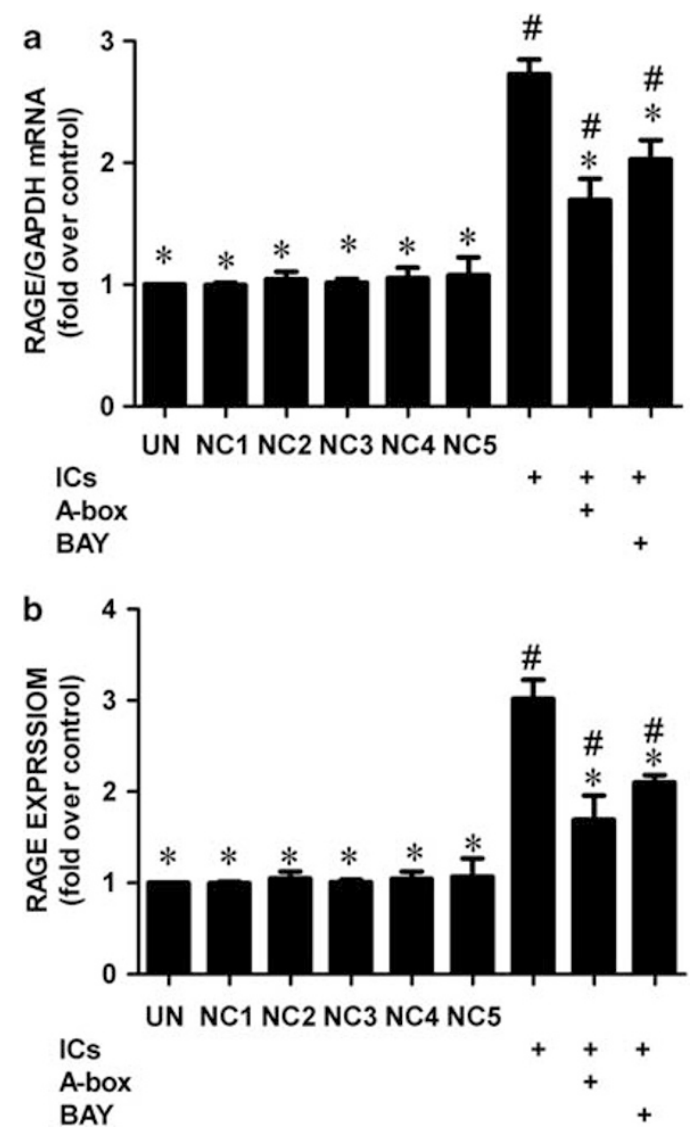

Figure 3 ICs upregulate RAGE expression, which can be partially blocked by HMGB1 A-box or Bay 117082 in human CRL-1730 cells. Human CRL1730 cells were treated with ICs or negative controls as described in the Methods or pretreated with either HMGB1 A-box $(10 \mu \mathrm{g} / \mathrm{ml})$ or Bay $117082\left(10^{-6} \mathrm{M}\right)$ for $1 \mathrm{~h}$ before treatment with ICs. (a) After incubation for $6 \mathrm{~h}$, RAGE mRNA expression was detected by quantitative real-time PCR. Results are presented as the fold increases as compared with unstimulated cells. Bars represent the means \pm s.e. ${ }^{\#} P<0.05$ as compared with unstimulated cells $(n=3),{ }^{*} P<0.05$ as compared with IC-stimulated cells $(n=3)$. (b) After incubation for $16 \mathrm{~h}$, cell surface expression of RAGE protein was detected by flow cytometry. Results are presented as the fold increases as compared with unstimulated cells. Bars represent the means \pm s.e. ${ }^{\#} P<0.05$ as compared with unstimulated cells $(n=3)$, ${ }^{*} P<0.05$ as compared with IC-stimulated cells $(n=3)$. UN: unstimulated CRL-1730 cells; NC1: IgG from healthy donors alone; NC2: lupus IgG alone; NC3: supernatants of untreated U937 cells, and IgG from healthy donors; NC4: supernatants of untreated U937 cells and lupus IgG; NC5: supernatants of UV-treated U937 cells, and IgG from healthy donors; A-box: HMGB1 A-box; BAY: Bay 117082.

The data suggest that the ICs induced upregulation of human endothelial cell surface receptor RAGE expression involving the cell-signaling HMGB1-RAGE axis.

\section{ICs Upregulate Cell Surface Expression of Both ICAM-1 and VCAM-1 and Involves the Signaling via the HMGB1- RAGE Axis in Human Endothelial Cells}

ICAM-1 and VCAM-1 are important cellular adhesion molecules in human endothelial cells. ${ }^{31,32}$ Human CRL-1730 cells were pretreated with HMGB1 A-box $(10 \mu \mathrm{g} / \mathrm{ml})$, sRAGE 
$(20 \mu \mathrm{g} / \mathrm{ml})$, Bay $117082(1 \mu \mathrm{M})$ or a combination of these agents, respectively, for $1 \mathrm{~h}$ before treatment with ICs. The purpose of this experiment was to determine whether ICs affect the expression of ICAM- 1 and VCAM-1 and to explore the potential mechanisms.

Human CRL-1730 cells that were incubated with ICs for $6 \mathrm{~h}$ showed an approximate three- to fourfold increase in both ICAM-1 and VCAM-1 mRNA levels $(P<0.05$, Figures $4 a$ and $b$ ). Pretreatment with HMGB1 A-box, sRAGE or Bay 117082 for $1 \mathrm{~h}$ before stimulation with ICs, suppressed the increase in ICAM-1 and VCAM-1 mRNA expression in human CRL-1730 cells $(P<0.05$, Figures $4 \mathrm{a}$ and $\mathrm{b})$. Analysis of cell surface ICAM-1 and VCAM-1 receptor expression by FCM (Figures 4c and d) and cellular ELISA (Supplementary Figure $\mathrm{S} 4 \mathrm{~A}$ and $4 \mathrm{~B}$ ) showed that their expression was consistent with the mRNA expression levels following incubation of human CRL-1730 cells with HMGB1 A-box, sRAGE or Bay 117082 for $1 \mathrm{~h}$ before treatment with ICs for $16 \mathrm{~h}$. In addition, pretreatment of human CRL-1730 cells with combinations of HMGB1 A-box and sRAGE or combinations of HMGB1 A-box, sRAGE and Bay 117082 for $1 \mathrm{~h}$ before treatment with ICs showed approximately the same effects (Figure 4 and Supplementary Figure S4) as the singular inhibitory effects of these blocking agents but not the combined effects of the singular inhibitory effects of the blocking agents. These observations indicated that the activating effects of ICs on human endothelial cells was partially blocked by HMGB1 A-box, sRAGE and Bay117082 in series.

These data further suggest that ICs upregulate the cell surface expression of both ICAM-1 and VCAM- 1 and does in a cell-signaling pathway dependent on the HMGB1-RAGE axis in human endothelial cells.

\section{ICs Increase Secretion of the Chemokines IL-8, MCP-1 and the Proinflammatory Cytokines IL- 6 , TNF- $\alpha$, Involves the Signaling via the HMGB1-RAGE Axis in Human Endothelial Cells}

Human CRL-1730 cells were treated with ICs to explore the effects of ICs on endothelial cell cytokine secretion. Quantitative real-time PCR was performed after incubation for $6 \mathrm{~h}$ to detect changes in the mRNA levels. A significant upregulation of IL-8 (Supplementary Figure S5A), MCP-1 (Supplementary Figure S5B), IL-6 (Supplementary Figure S5C) and TNF- $\alpha$ (Supplementary Figure S5D) mRNA levels was observed in cells stimulated with ICs $(P<0.05)$. When human CRL-1730 cells were pretreated with HMGB1 A-box
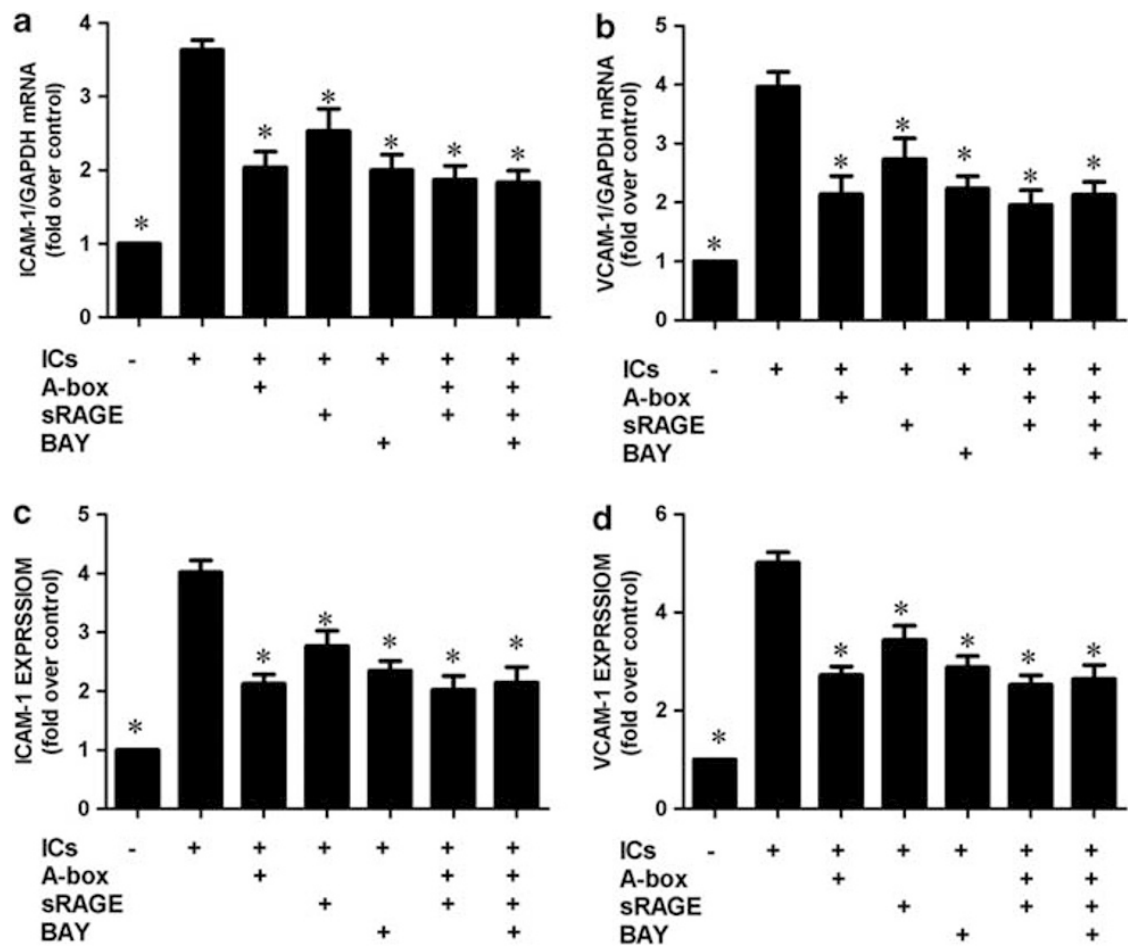

Figure 4 ICs upregulate ICAM-1 and VCAM-1 expression, which can be partially blocked by HMGB1 A-box, sRAGE, Bay 117082 or by those agents used in combination in human CRL-1730 cells. Human CRL-1730 cells were pretreated with HMGB1 A-box (10 $\mu \mathrm{g} / \mathrm{ml})$, sRAGE (20 $\mu \mathrm{g} / \mathrm{ml}), \mathrm{Bay} 117082$ $\left(10^{-6} \mathrm{M}\right)$ or the agents used in combination for $1 \mathrm{~h}$ before treatment with ICs. (a, b) After incubation for $6 \mathrm{~h}$, ICAM-1 and VCAM-1 mRNA expression was detected by quantitative real-time PCR. Results are presented as the fold increases as compared with negative control cells. Bars represent the means \pm s.e. ${ }^{*} P<0.05$ as compared with ICs-stimulated cells $(n=3)$. (c, d) After incubation for 16 h, cell surface ICAM- 1 and VCAM- 1 protein expression was detected by flow cytometry. Results are presented as fold increases as compared with negative control cells. Bars represent the means \pm s.e. ${ }^{*} P<0.05$ as compared with ICs-stimulated cells $(n=3)$. Human CRL-1730 cells treated with supernatants of untreated U937 cells and IgG from healthy donors served as negative control. A-box, HMGB1 A-box; BAY, Bay 117082. 

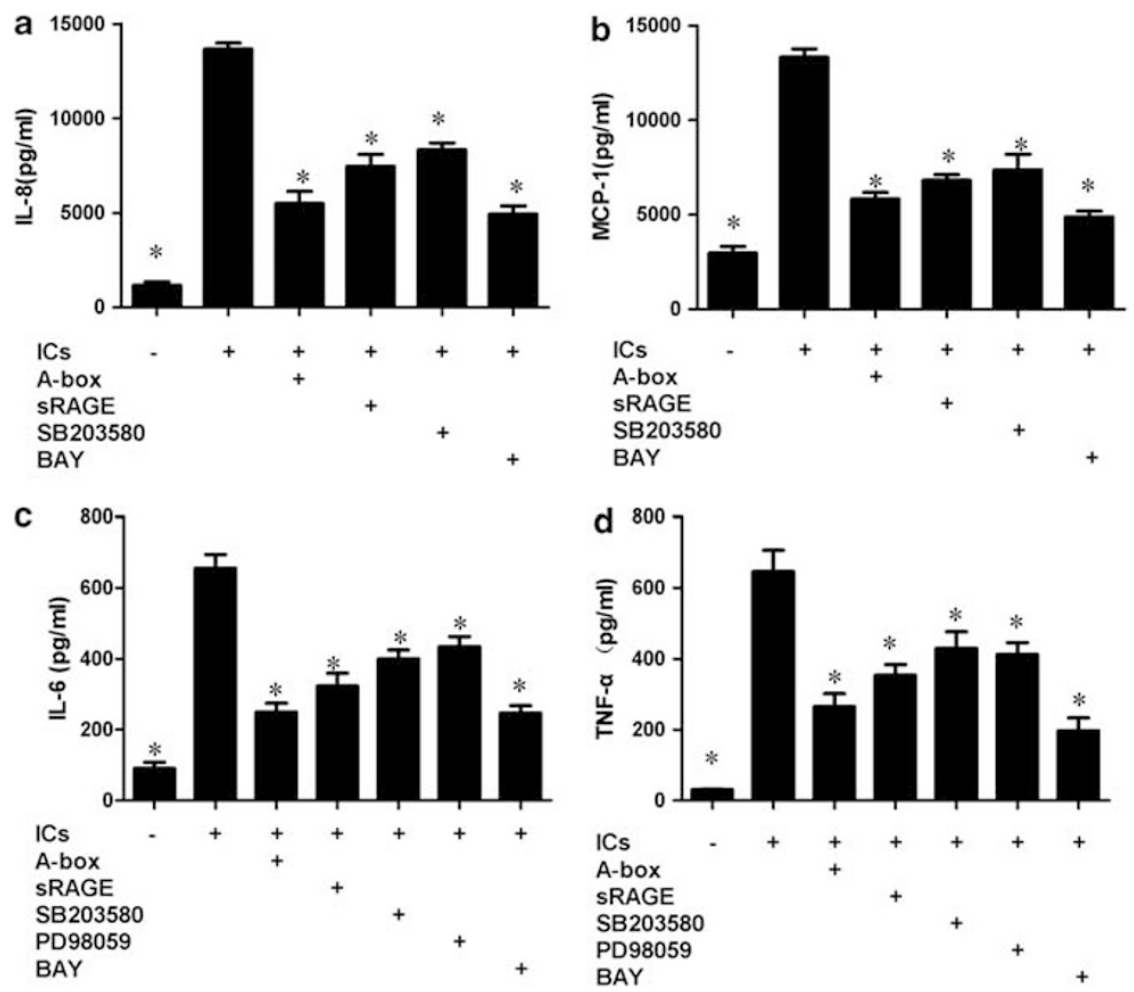

Figure 5 ICS increase the secretion of the cytokines IL-8, MCP-1, IL-6 and TNF- $\alpha$ in human CRL-1730 cells, which can be partially blocked by HMGB1 A-box, sRAGE, SB203580, PD98059 or Bay117082. Human CRL-1730 cells were pretreated with HMGB1 A-box (10 $\mu \mathrm{g} / \mathrm{ml})$, sRAGE (20 $\mu \mathrm{g} / \mathrm{ml}), \mathrm{SB} 203580$ $(10 \mu \mathrm{M})$, PD98059 $(25 \mu \mathrm{M})$ or Bay $117082\left(10^{-6} \mathrm{M}\right)$ for $1 \mathrm{~h}$ before treatment with ICs. After incubation for $24 \mathrm{~h}$, the secretion of IL-8 (a), MCP-1 (b), IL-6 (c) and TNF- $\alpha$ (d) in the cell-free supernatant was determined by ELISA. Three independent experiments yielded similar results. Bars represent the means \pm s.e. ${ }^{*} P<0.05$ as compared with ICs-stimulated cells $(n=3)$. Human CRL-1730 cells treated with supernatants derived from untreated U937 cells and IgG from healthy donors served as negative control group. A-box, HMGB1 A-box; BAY, Bay 117082.

$(10 \mu \mathrm{g} / \mathrm{ml})$, sRAGE $(20 \mu \mathrm{g} / \mathrm{ml})$ or Bay $117082(1 \mu \mathrm{M})$ for $1 \mathrm{~h}$ before treatment with ICs for $6 \mathrm{~h}$, there was profound suppression of the mRNA levels of these cytokines $(P<0.05$, Supplementary Figure S5). Inhibitors agents of NF- $\kappa \mathrm{B}$ activation significantly reduced the mRNA expression of these cytokines $(P<0.01)$. Corresponding protein expression was also determined in human CRL-1730 cells treated as described for $24 \mathrm{~h}$. It was found that treatment with ICs significantly increased secretion $(P<0.05)$ of IL-8 (Figure 5a), MCP-1 (Figure 5b), IL-6 (Figure 5c) and TNF- $\alpha$ (Figure 5d). These increases were partially blocked by HMGB1A-box, sRAGE and Bay $117082(P<0.05$, Figure 5). Bay 117082 was found to mediate the greatest decrease in cytokine secretion levels $(P<0.01)$. Collectively, these data indicated that ICs significantly increase IL-8, MCP-1, IL- 6 and TNF- $\alpha$ mRNA levels as well as protein secretion in human endothelial cells and that this process involved the HMGB1-RAGE axis signaling pathway.

\section{Contribution of p38 MAPK and ERK1/2 Pathways in the Cell-Signaling HMGB1-RAGE Axis Induced by ICs in Human Endothelial Cells}

Human CRL-1730 cells were pretreated with specific inhibitors of p38 MAPK (SB203580, $10 \mu \mathrm{M})$ and ERK1/2
(PD98059, $25 \mu \mathrm{M}$ ) for $1 \mathrm{~h}$ before treatment with ICs. We found that SB203580 decreased the mRNA levels of IL-8, MCP-1, IL- 6 and TNF- $\alpha$, and that PD98059 decreased the mRNA levels of IL- 6 and TNF- $\alpha$ after incubation for $6 \mathrm{~h}$ as compared with IC-stimulated cells $(P<0.05$, Supplementary Figure S5). ELISA of IL-8, IL-6, MCP- 1 and TNF- $\alpha$ protein levels in cell-free supernatants after incubation for $24 \mathrm{~h}$ showed good agreement with the mRNA levels $(P<0.05$, Figure 5).

These data indicated that ICs significantly increased IL-8, IL-6, MCP- 1 and TNF- $\alpha$ mRNA levels and protein secretion in human CRL-1730 cells and that this process is mediated by signaling through the p38 MAPK and ERK1/2 pathways, which are involved in the cell-signaling HMGB1-RAGE axis.

\section{ICs Activate NF- $\kappa$ B p65, Involves the Signaling via the HMGB1-RAGE Axis in Human Endothelial Cells}

The former results in our study demonstrated that the inhibitor of p65 can inhibit the expression of cytokines induced by ICs on human endothelial cells. In this experiment, we attempted to further demonstrate that the effects of ICs on activating human endothelial cells lead to subsequent activation of NF- $\kappa \mathrm{B}$ p65 and the involvement of the HMGB1-RAGE cell-signaling axis. We found that ICs 
a

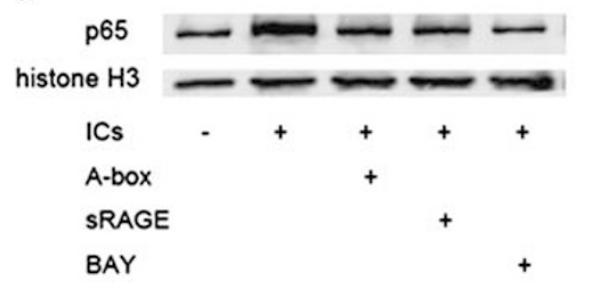

b

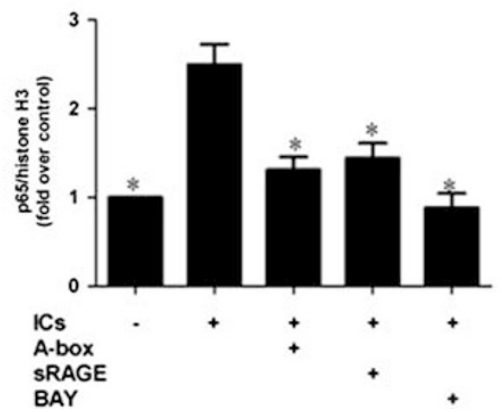

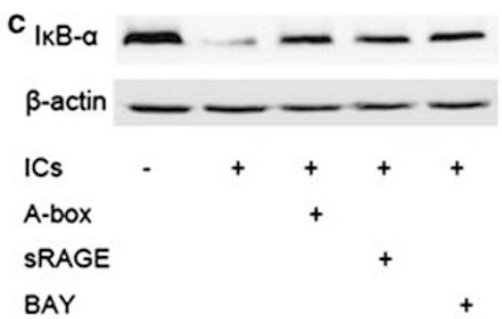

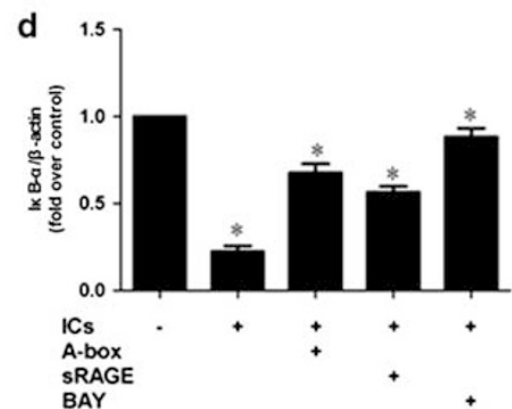

Figure 6 ICs activate NF- $\kappa$ B p65 in human CRL-1730 cells, which can be partially blocked by HMGB1 A-box, sRAGE and Bay 117082 . Human CRL-1730 cells were pretreated with HMGB1 A-box $(10 \mu \mathrm{g} / \mathrm{ml})$, sRAGE $(20 \mu \mathrm{g} / \mathrm{ml})$ or Bay $117082\left(10^{-6} \mathrm{M}\right)$ for $1 \mathrm{~h}$ before treatment with ICs. After incubation for $2 \mathrm{~h}$, (a) p65 protein levels in the nucleus were analyzed by western blot. Equal loading of nuclear protein was confirmed by staining for histone $\mathrm{H} 3$. Three independent experiments yielded similar results, of which one out of three is shown here. (b) Densitometric analysis of three independent western blot experiments showing p65 protein levels in the nucleus normalized to histone H3. Bars represent the means \pm s.e. ${ }^{*} P<0.05$ compared with ICs-stimulated cells $(n=3)$. (c) I $\kappa \mathrm{B}-\alpha$ levels in the cytoplasm were analyzed by western blot. Equal loading of cytoplasmic protein was confirmed by staining for $\beta$-actin. Three independent experiments yielded similar results. One representative result out of three is shown. (d) Densitometric analysis of three independent western blot experiments showing $\mid \kappa \mathrm{B}-\alpha$ protein levels in the cytoplasm normalized to $\beta$-actin. Bars represent the means \pm s.e. ${ }^{*} P<0.05$ as compared with ICs-stimulated cells $(n=3)$. Human CRL-1730 cells treated with supernatants of untreated U937 cells and IgG from healthy donors served as negative control cell group. A-box, HMGB1 A-box; BAY, Bay117082.

increased nuclear import of NF- $\kappa \mathrm{B}$ p 65 in human endothelial cells after $2 \mathrm{~h}$ treatment with ICs (Supplementary Figures S6 and S7). We pretreated human CRL-1730 cells with HMGB1 A-box $(10 \mu \mathrm{g} / \mathrm{ml})$, sRAGE $(20 \mu \mathrm{g} / \mathrm{ml})$ or Bay $117082(1 \mu \mathrm{M})$ for $1 \mathrm{~h}$ before treatment with ICs. After incubation for $2 \mathrm{~h}$, p65 levels in the nucleus and the levels of the inhibitory protein $\mathrm{I} \kappa \mathrm{B}-\alpha$ levels in the cytoplasm were analyzed. ICs increased the nuclear level of p65 by $>200 \%(P<0.05)$, and these effects were inhibited by HMGB1 A-box, sRAGE and Bay $117082(P<0.05$, Figures $6 \mathrm{a}$ and $\mathrm{b})$. The expression of $\mathrm{I} \kappa \mathrm{B}-\alpha$ levels in the cytoplasm (Figures $6 \mathrm{c}$ and $\mathrm{d}$ ) showed that ICs stimulated $\mathrm{I} \kappa \mathrm{B}-\alpha$ degradation in the cytoplasm and that this could be blocked by HMGB1 A-box, sRAGE and Bay $117082(P<0.05)$. Collectively, these data suggest that stimulation of human endothelial cells by ICs lead to the degradation of the inhibitory protein $\mathrm{I} \kappa \mathrm{B}-\alpha$ in the cytoplasm and the release of the transcription factor NF- $\kappa \mathrm{B}$ p 65 , which then translocate into the nucleus. This process involved cell signaling via the HMGB1-RAGE axis.

\section{Monocyte Transendothelial Migration is Enhanced by Pretreatment of Human Endothelial Cells with ICs, which Occurs Involves the Signaling via the HMGB1-RAGE Axis in Human Endothelial Cells}

Monocyte transendothelial migration has a primary role in the recruitment of monocytes to the inflammatory sites, which is a key event in the pathogenesis of lupus vasculitis. 6,7
Recent studies on lupus vasculitis and nephritis showed that activated monocytes and macrophages vigorously participate in, and amplify inflammation, which influences the outcome of the condition. ${ }^{33-35}$

In these experiments, transwell chambers were used to detect the effect of IC-pretreated CRL-1730 cells and the transendothelial migration of U937 cells as compared with negative control CRL-1730 cells. Pretreatment of human CRL-1730 cells with ICs triggered an approximate fourfold increase in monocyte migration across the CRL-1730 monolayer to the bottom chamber as compared with the negative control cells $(P<0.05$, Figure 7$)$. This process was markedly reduced by pretreating the human CRL-1730 cells with HMGB1 A-box $(10 \mu \mathrm{g} / \mathrm{ml})$, sRAGE $(20 \mu \mathrm{g} / \mathrm{ml})$ or Bay $117082\left(10^{-6} \mathrm{M}\right)$ for $1 \mathrm{~h}$ before stimulation with ICs $(P<0.05$, Figure 7$)$. Additionally, pretreatment of human CRL-1730 cells with a combination of HMGB1 A-box and sRAGE or a combination of HMGB1 A-box, sRAGE and Bay 117082 for $1 \mathrm{~h}$ before treatment with ICs showed similar effects (Figure 7) as the singular inhibitory effects of the blocking agents but not in the context of the combined effects of the blocking agents used alone. This observation indicated that the increased transendothelial migration of monocytes induced by IC-stimulated endothelial cells can be partially blocked by HMGB1 A-box, sRAGE and Bay 117082 in series.

These observations collectively show that monocyte transendothelial migration is enhanced by IC-pretreated 


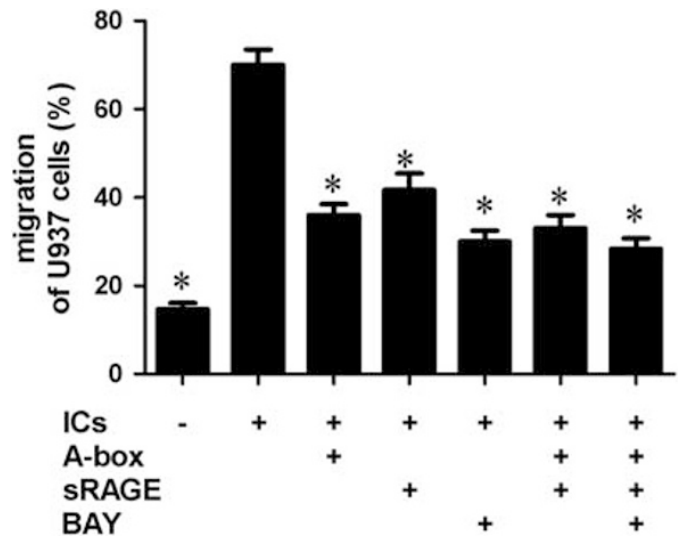

Figure 7 ICs pretreated human CRL-1730 cells increase the transendothelial migration of U937 cells, which can be partially inhibited by HMGB1 A-box, SRAGE, Bay 117082 or combinations of all agents. Human CRL-1730 cells were first seeded on gelatin-coated permeable Transwell filters to form a monolayer. Cells were first pretreated with HMGB1 A-box $(10 \mu \mathrm{g} / \mathrm{ml})$, sRAGE $(20 \mu \mathrm{g} / \mathrm{ml})$, Bay $117082\left(10^{-6} \mathrm{M}\right)$ or a combination of all of these agents for $1 \mathrm{~h}$ before treatment with ICs. After incubation for $24 \mathrm{~h}$, human U937 cells were added to the upper chambers and allowed to migrate for $20 \mathrm{~h}$. Monocytes that had migrated to the lower chamber were counted using a TC10 Automated Cell Counter. Results are presented as the percentage of U937 cells that migrated to the lower chamber of the total U937 cells added to the upper chamber. Bars represent means \pm s.e. $(n=3)$. ${ }^{*} P<0.05$ as compared with ICs-stimulated cells. Human CRL-1730 cells treated with supernatants of untreated U937 cells and IgG from healthy donors served as negative control. A-box, HMGB1 A-box; BAY, Bay 117082.

human endothelial cells, which involves cell signaling via the HMGB1-RAGE axis in human endothelial cells. It also demonstrates that ICs elicit functional alteration of human endothelial cells via HMGB1-RAGE axis signaling.

\section{Cell Viability of Human Endothelial Cells Treated with HMGB1-A-box, sRAGE, Bay 117082, SB203580, PD98059 Alone or in Combination}

To verify that the inhibitory effects of HMGB1-A-box, sRAGE, Bay 117082, SB203580, PD98059 or combinations of them was not due to cytotoxic effects, we treated human CRL-1730 cells with HMGB1 A-box $(10 \mu \mathrm{g} / \mathrm{ml})$, sRAGE $(20 \mu \mathrm{g} / \mathrm{ml})$, SB203580 $(10 \mu \mathrm{M})$, PD98059 $(25 \mu \mathrm{M})$, Bayl17082 $(1 \mu \mathrm{M})$ or combinations of these agents in the same concentration used in the experiments and then determined cell viability $24 \mathrm{~h}$ later. We found that cell counts for all reagents tested remained statistically similar to the negative control cells after the incubation periods (Supplementary Figure S8A). Furthermore, Trypan blue staining (Supplementary Figure S8B) and CCK-8 assays(Supplementary Figure S8C) both showed that cells stimulated with these reagents remained viable after $24 \mathrm{~h}$. We concluded that all of these blocking agents used either alone or in combination used in the experiments were not toxic to human CRL-1730 cells.

\section{DISCUSSION}

The molecules and cytokines examined in this study are activation markers of human endothelial cells. RAGE is a very important receptor, which is expressed on the surface of human endothelial cells, and following activation, signals to the NF- $\kappa \mathrm{B}$ p65 transcription factor through the classical activation pathway and thus evokes enhanced secretion of a series of cytokines. ${ }^{14}$ Both ICAM-1 and VCAM-1, which are important adhesion molecules expressed on the cell surface of endothelial cells, belong to the immunoglobulin superfamily and are receptors for LFA-1 and VLA-4, respectively. Both these two adhesion molecules contribute to the adhesion of monocytes and other leukocytes to endothelial cells at the sites of inflammation. ${ }^{31,32}$ Both IL-8 and MCP-1, which are potent chemoattractants for monocytes, are essential for monocyte adhesion and subsequent transmigration through endothelial monolayers and thus facilitate the recruitment of monocytes to sites of inflammation. ${ }^{36,37}$ MCP-1 is a ligand for the G-proteincoupled receptor CCR2, and performs its role via activating monocytes that express CCR2, and promoting their subsequent migration. ${ }^{36,37}$ IL-6 is a proinflammatory factor, which is produced by endothelial cells, and when overexpressed leads to perpetuation of inflammation. ${ }^{38}$ TNF- $\alpha$ is a pivotal early mediator that regulates and amplifies inflammation. ${ }^{11}$ Additionally, the secretion of the proinflammatory factor IL-1 $\beta$ was not detected following stimulation with ICs (data not shown). We found from the results of our study that ICs enhance the expression of the cell surface receptor RAGE, ICAM-1 and VCAM- 1 and augment the secretion of IL- 8 , MCP-1, IL- 6 and TNF- $\alpha$. In addition, activation of NF- $\kappa$ B p 65 by IC-stimulated human endothelial cells was shown. In the results, the cell-signaling HMGB1-RAGE axis are proved to be involved in the ability of ICs to activate human endothelial cells in series by co-treatments of the inhibitors. So we conclude that the stimulatory effects of ICs involved cell signaling via the HMGB1-RAGE axis to the activation of NF- $\kappa \mathrm{B}$ p65, which leads to the degradation of the inhibitory protein $\mathrm{I} \kappa \mathrm{B}-\alpha$ in the cytoplasm and the release of the transcription factor $\mathrm{NF}-\kappa \mathrm{B}$ p65. Following translocation of NF- $\kappa \mathrm{B}$ p 65 into the nucleus, the expression of RAGE, ICAM-1, VCAM- 1 and secretion IL-8, IL-6, MCP-1 and TNF- $\alpha$ were regulated through the classical activation pathway in human endothelial cells. These observations were concordant with previous reports. ${ }^{14-18}$ This process contributes to the proinflammatory response and functional alterations in human endothelial cells, which has an important role in the pathogenesis of SLE vasculitis.

The observations made from the migration studies further suggest that ICs activate human endothelial cells and involves cell signaling via the HMGB1-RAGE axis, activation of NF- $\kappa \mathrm{B}$ p 65 , increased expression of ICAM- 1 and VCAM-1 and enhanced secretion of both IL-8 and MCP-1. These are conditions which assist in increasing the migration of monocytes across the human endothelium monolayer to inflammatory sites. This process has an important role in the pathogenesis of SLE vasculopathy and vasculitis. 
The p38 MAPK and ERK1/2 signaling pathways were also shown to be involved in cell signaling via the HMGB1-RAGE axis in response to IC-stimulated human endothelial cells. These observations corresponded well to previous reports suggesting the involvement of RAGE in the activation of key signal transduction pathways, including p21ras, ERK1/2 and $\mathrm{NF}-\kappa \mathrm{B}$ in endothelial cells, monocytes and vascular smooth muscle cells. This cascade of events leads to RAGE-mediated augmentation of the expression of proinflammatory mediators. ${ }^{14,16-18,24}$ It further demonstrates that the cell-signaling HMGB1-RAGE axis is involved in the activation of human endothelial cells by ICs.

The most commonly used method for IC preparation was employed in this study. ${ }^{2,27-30}$ The late apoptotic U937 cells release nucleic acids and nucleic acids-associated proteins in which HMGB1 is contained ${ }^{39}$ into the ICs, which was demonstrated by us (Figure 2). We also found that the purified lupus IgG contained corresponding autoantibodies of the ICs. We examined the types of autoantibodies of all the of patients presenting with SLE is our study and pooled all the serum samples from these patients to purify the lupus IgG for use in subsequent experiments as previously described. ${ }^{2,27-30}$ The identification of late apoptosis in U937 cells was done by FCM analysis according to the references, ${ }^{2,27-30}$ and the identification of the HMGB1 component in the ICs and negative controls was further confirmed by western immunoblot.

By analyzing the components of the ICs and the negative controls, it was found that nucleic acids and nucleic acid-associated proteins in which HMGB1 is contained, are released from late apoptotic U937 cells. They were not detected in the supernatants of untreated U937 cells. This observation corresponded to the origin of nucleic acids and nucleic acid-associated protein HMGB1 described in the introduction. The corresponding autoantibodies were contained in the purified lupus IgG and were not detected in the healthy blood donors. Comparing the effects of ICs and the negative controls described above, we conclude that the effects of ICs on human endothelial cells are entirely due to the whole effect of the ICs, which contains three components. Each component of the IC is essential in the ability of ICs to activate human endothelial cells. These results correspond to other studies showing the ability of ICs to stimulate IFN- $\alpha$ secretion by plasmacytoid dendritic cells (pDCs), ${ }^{2,27-30}$ which demonstrated that combinations of supernatants of late apoptotic U937 cells and lupus IgG are much more effective than the supernatants of late apoptotic U937 cells or lupus IgG when used alone or as compared with other negative controls on the secretion of IFN- $\alpha$ by pDCs. ${ }^{2}$ These observations also correspond to previous reports showing that the effective components of ICs are endogenous nucleic acids CpG-A, HMGB1 and lupus $\operatorname{IgG}^{1,3}$ and that HMGB1 combined with CpG-A are more effective in their activating effects than either of these agents used alone. ${ }^{1}$ Different components in the ICs influence and modulate each other's functions ${ }^{1,2}$ during the process of IC formation. This leads to an enhancement of their separate activating effects on cells. Consequently, it can be further concluded that the effects of the HMGB1 component in the ICs, which were evaluated in our study, were quite different from the effects of HMGB1 protein alone on the endothelial cells.

As ICs are biological complexes, it may be complicated and very challenging to explore their exact mechanisms of activation of endothelial cells. Thus, in our study, we selected one cell-signaling pathway to evaluate whether it was involved in the observed effects and to determine if it could be a potential mechanism responsible for the effects of ICs on human endothelial cells. We explored this by using specific blocking agents. From our study, it was found that the cellsignaling HMGB1-RAGE axis was a crucial mechanism involved in the activation of human endothelial cell by ICs. Blocking agents were found to be non-toxic to human CRL1730 cells, supporting the notion that the inhibitory effects of the blockers was not due to any cytotoxicity. Dose-response assays of the blocking agents were also explored in our study (data not shown) to demonstrate that the partial inhibition of the HMGB1-RAGE cell-signaling pathway was not due to a dose-dependent effect of the blockers. This further demonstrated that the HMGB1-RAGE cell-signaling axis is partially involved in the activating effects on human endothelial cells induced by ICs in SLE. Other cell-signaling pathways also contributed to the effects, which is interesting, relevant and requires further exploration. It has been previously reported that stimulatory type A CpG-DNA induces responses in human endothelial cells $^{40}$ and that antibodies can bind to endothelial Fc receptors. ${ }^{41,42}$ The mechanisms related to these two components in the ICs on human endothelial cells require further evaluation.

In addition to ICs, other cytokines present in the serum in SLE may have a role in the abnormal activation of human endothelial cells. The proinflammatory factors shown to be upregulated by ICs in this study can further induce endothelial inflammation, such as TNF- $\alpha$, a cytokine which is a potent activator of endothelial cells. ${ }^{11}$ TNF- $\alpha$ was also used as a positive control in our study, because it has been previously shown ${ }^{17}$ that it can activate human endothelial cells and the transcription factor NF- $\kappa \mathrm{B}$ as compared with the effect of ICs (data not shown).

In conclusion, this study has demonstrated that ICs elicit proinflammatory responses in human endothelial cells and contributes to alterations in human endothelial cell function that involved cell signaling through the HMGB1-RAGE axis. It provides a demonstration for the effects and provided a potential mechanistic framework to further our understanding of the effects of ICs on human endothelial cells. This is important in furthering our understanding of the pathogenesis of lupus vasculitis, and it may also provide supporting evidence for future therapeutic management of SLE vasculitis. 
Supplementary Information accompanies the paper on the Laboratory Investigation website (http://www.laboratoryinvestigation.org)

\section{ACKNOWLEDGEMENTS}

This work was supported by National Key Technology Research and Development Program (2011BAl17B00) National Basic Research Program of China (973 Program) (2012CB944700)

\section{DISCLOSURE/CONFLICT OF INTEREST}

The authors declare no conflict of interest.

1. Tian J, Avalos AM, Mao SY, et al. Toll-like receptor 9-dependent activation by DNA-containing immune complexes is mediated by HMGB1 and RAGE. Nat Immunol 2007:8:487-496.

2. Lovgren $\mathrm{T}$, Eloranta $\mathrm{ML}$, Bave $\mathrm{U}$, et al. Induction of interferon-alpha production in plasmacytoid dendritic cells by immune complexes containing nucleic acid released by necrotic or late apoptotic cells and lupus IgG. Arthritis Rheum 2004;50:1861-1872.

3. Urbonaviciute $\mathrm{V}$, Furnrohr BG, Meister $\mathrm{S}$, et al. Induction of inflammatory and immune responses by HMGB1-nucleosome complexes: implications for the pathogenesis of SLE. J Exp Med 2008;205:3007-3018.

4. Herrmann M, Voll RE, Zoller OM, et al. Impaired phagocytosis of apoptotic cell material by monocyte-derived macrophages from patients with systemic lupus erythematosus. Arthritis Rheum 1998;41:1241-1250.

5. Munoz LE, Janko C, Grossmayer GE, et al. Remnants of secondarily necrotic cells fuel inflammation in systemic lupus erythematosus. Arthritis Rheum 2009:60:1733-1742.

6. Cieslik P, Hrycek A, Klucinski P. Vasculopathy and vasculitis in systemic lupus erythematosus. Pol Arch Med Wewn 2008;118:57-63.

7. Calamia KT, Balabanova M. Vasculitis in systemic lupus erythematosis. Clin Dermatol 2004:22:148-156.

8. Bradley JR, Lockwood CM, Thiru S. Endothelial cell activation in patients with systemic vasculitis. QJM 1994;87:741-745.

9. Jurd KM, Stephens CJ, Black MM, et al. Endothelial cell activation in cutaneous vasculitis. Clin Exp Dermatol 1996;21:28-32.

10. Pan HF, Wu GC, Li WP, et al. High Mobility Group Box 1: a potentia therapeutic target for systemic lupus erythematosus. Mol Biol Rep, 37:1191-1195.

11. Ma CY, Jiao YL, Zhang J, et al. Elevated plasma level of HMGB1 is associated with disease activity and combined alterations with IFN-alpha and TNF-alpha in systemic lupus erythematosus. Rheumatol Int, 32:395-402.

12. Abdulahad DA, Westra J, Limburg PC, et al. HMGB1 in systemic lupus erythematosus: its role in cutaneous lesions development. Autoimmun Rev, 9:661-665.

13. Qing X, Pitashny M, Thomas DB, et al. Pathogenic anti-DNA antibodies modulate gene expression in mesangial cells: involvement of HMGB1 in anti-DNA antibody-induced renal injury. Immunol Lett 2008;121: 61-73.

14. Bierhaus $A$, Humpert $P M$, Morcos $M$, et al. Understanding RAGE, the receptor for advanced glycation end products. J Mol Med 2005;83:876-886.

15. Liang $Y$, Zhou Y, Shen P. NF-kappaB and its regulation on the immune system. Cell Mol Immunol 2004;1:343-350.

16. Yeh $\mathrm{CH}$, Sturgis $\mathrm{L}$, Haidacher J, et al. Requirement for $\mathrm{p} 38$ and $\mathrm{p} 44 / \mathrm{p} 42$ mitogen-activated protein kinases in RAGE-mediated nuclear factorkappaB transcriptional activation and cytokine secretion. Diabetes 2001:50:1495-1504.

17. Hayden MS, Ghosh S. Signaling to NF-kappaB. Genes Dev 2004:18:2195-2224.

18. Hoffmann A, Natoli G, Ghosh G. Transcriptional regulation via the NF-kappaB signaling module. Oncogene 2006;25:6706-6716.

19. Yang $\mathrm{H}$, Ochani $\mathrm{M}, \mathrm{Li} \mathrm{J}$, et al. Reversing established sepsis with antagonists of endogenous high-mobility group box 1. Proc Natl Acad Sci USA 2004;101:296-301.

20. Kokkola R, Li J, Sundberg $E$, et al. Successful treatment of collageninduced arthritis in mice and rats by targeting extracellular high mobility group box chromosomal protein 1 activity. Arthritis Rheum 2003;48:2052-2058.

21. Li M, Shang DS, Zhao WD, et al. Amyloid beta interaction with recepto for advanced glycation end products up-regulates brain endothelial CCR5 expression and promotes $T$ cells crossing the blood-brain barrier. J Immunol 2009;182:5778-5788.

22. Hsieh HL, Schafer BW, Weigle B, et al. S100 protein translocation in response to extracellular $\mathrm{S} 100$ is mediated by receptor for advanced glycation endproducts in human endothelial cells. Biochem Biophys Res Commun 2004:316:949-959.

23. Skurk T, van Harmelen V, Hauner $\mathrm{H}$. Angiotensin II stimulates the release of interleukin- 6 and interleukin-8 from cultured human adipocytes by activation of NF-kappaB. Arterioscler Thromb Vasc Biol 2004:24:1199-1203.

24. Basta G, Lazzerini G, Massaro $M$, et al. Advanced glycation end products activate endothelium through signal-transduction recepto RAGE: a mechanism for amplification of inflammatory responses. Circulation 2002:105:816-822.

25. Rasheed Z, Akhtar N, Haqqi TM. Advanced glycation end products induce the expression of interleukin- 6 and interleukin-8 by receptor for advanced glycation end product-mediated activation of mitogenactivated protein kinases and nuclear factor-kappaB in human osteoarthritis chondrocytes. Rheumatology (Oxford), 50:838-851.

26. Shanmugam N, Kim YS, Lanting L, et al. Regulation of cyclooxygenase2 expression in monocytes by ligation of the receptor for advanced glycation end products. J Biol Chem 2003;278:34834-34844.

27. Bave U, Alm GV, Ronnblom L. The combination of apoptotic U937 cells and lupus IgG is a potent IFN-alpha inducer. J Immunol 2000;165:3519-3526.

28. Bave U, Vallin $\mathrm{H}, \mathrm{Alm} \mathrm{GV}$, et al. Activation of natural interferon-alpha producing cells by apoptotic U937 cells combined with lupus IgG and its regulation by cytokines. J Autoimmun 2001;17:71-80.

29. Bave U, Magnusson M, Eloranta ML, et al. Fc gamma Rlla is expressed on natural IFN-alpha-producing cells (plasmacytoid dendritic cells) and is required for the IFN-alpha production induced by apoptotic cells combined with lupus IgG. J Immunol 2003;171:3296-3302.

30. Vallin H, Perers A, Alm GV, et al. Anti-double-stranded DNA antibodies and immunostimulatory plasmid DNA in combination mimic the endogenous IFN-alpha inducer in systemic lupus erythematosus. J Immunol 1999:163:6306-6313.

31. Haraldsen G, Kvale D, Lien B, et al. Cytokine-regulated expression of E-selectin, intercellular adhesion molecule-1 (ICAM-1), and vascular cell adhesion molecule-1 (VCAM-1) in human microvascular endothelial cells. J Immunol 1996:156:2558-2565.

32. Smith CW. Leukocyte-endothelial cell interactions. Semin Hematol 1993:30(4 Suppl 4):45-53, discussion 54-45.

33. Akashi $\mathrm{Y}$, Oshima $\mathrm{S}$, Takeuchi $\mathrm{A}$, et al. [Identification and analysis of immune cells infiltrating into the glomerulus and interstitium in lupus nephritis]. Nihon Rinsho Meneki Gakkai Kaishi 1995;18:545-551.

34. Hill GS, Delahousse M, Nochy D, et al. Predictive power of the second renal biopsy in lupus nephritis: significance of macrophages. Kidney Int 2001;59:304-316.

35. Isbel NM, Nikolic-Paterson DJ, Hill PA, et al. Local macrophage proliferation correlates with increased renal M-CSF expression in human glomerulonephritis. Nephrol Dial Transplant 2001;16: 1638-1647.

36. Popovic $M$, Laumonnier $Y$, Burysek $L$, et al. Thrombin-induced expression of endothelial CX3CL1 potentiates monocyte CCL2 production and transendothelial migration. J Leuk Biol 2008;84: 215-223.

37. Zoja $\mathrm{C}$, Angioletti $\mathrm{S}$, Donadelli $\mathrm{R}$, et al. Shiga toxin-2 triggers endothelial leukocyte adhesion and transmigration via NF-kappaB dependent up-regulation of IL-8 and MCP-1. Kidney Int 2002;62: 846-856.

38. Hooper WC, Phillips DJ, Renshaw MA, et al. The up-regulation of IL-6 and IL-8 in human endothelial cells by activated protein C. J Immunol 1998;161:2567-2573.

39. Bell CW, Jiang W, Reich 3rd CF, et al. The extracellular release of HMGB1 during apoptotic cell death. Am J Physiol 2006;291: C1318-C1325.

40. Fitzner N, Zahner L, Habich C, et al. Stimulatory type A CpG-DNA induces a Th2-like response in human endothelial cells. Int Immunopharmacol 2011;11:1789-1795. 
41. Cabeza N, Li Z, Schulz C, et al. Surface expression of collagen receptor Fc receptor-gamma/glycoprotein $\mathrm{VI}$ is enhanced on platelets in type 2 diabetes and mediates release of CD40 ligand and activation of endothelial cells. Diabetes 2004;53:2117-2121.
42. Florey OJ, Johns M, Esho OO, et al. Antiendothelial cell antibodies mediate enhanced leukocyte adhesion to cytokine-activated endothelial cells through a novel mechanism requiring cooperation between Fc\{gamma\}RIla and CXCR1/2. Blood 2007;109:3881-3889. 